\title{
Pupillary responses during mental activities
}

THEODORE SCHAEFER, JR., J. BRINTON FERGUSON, JOSEPH A. KLEIN, AND EDWARD B. RAWSON, SCIENCE \& ENGINEERING, Inc., Waltham, Massachusetts 02154

With a new electronic technique, pupil size of $40 \mathrm{Ss}$ was measured continuously during a series of intellectual tasks. Time estimation or counting elicited no pupillary changes, but pupil diameter reliably increased (approximately 30\%) during number memory, multiplication, and word definition. Dilation was greater for novel or more difficult tasks. If $S$ continued to work a problem after answering, dilation persisted, but silent counting by $S$ terminated task perseveration and dilation. Thinking about pleasant or unpleasant experiences elicited inconsistent dilation, constriction, or no change.

A new instrument permits continuous, real-time read-out of eye movements and pupil size. A collimated infrared beam is retroreflected from the retina through the pupil onto a star-tracker photocathode, thus avoiding difficulties with corneal highlights and iris-pupil brightness contrasts. The electronic output is suitable for on-line display or recording, analog-to-digital conversion, or computer processing. To evaluate the reported relationship between pupillary response and mental activity, 40 Ss were tested in situations similar to those of Hess \& Polt (1964), Kahneman \& Beatty (1966), and Bernick \& Oberlander (1968). Method

Four females and 36 males, 19 to 50 years old with high school through doctorate education, were read instructions explaining the apparatus and the testing procedure, and emphasizing the goal of exploring visual responses and evaluating the instrument rather than the S. S sat, head positioned in a hood, looking through a circular $3 \mathrm{~cm}$ aperture in a vertical white cardboard screen $20 \mathrm{~cm}$ from S's eye. The infrared source provided a fixation target visible to $S$ as a dim red (Wratten No. 87) disc at optical infinity, subtending $3 \mathrm{deg}$ of visual angle. After $60 \mathrm{sec}$ dark adaptation, pupil diameter was reduced to 4 or $5 \mathrm{~mm}$ by adjusting two $40-\mathrm{W}$ fluorescent tubes illuminating the white screen.

Horizontal pupil diameter, vertical and horizontal eye movements, and S-R events were displayed separately on a 5-channel recorder. For some Ss, additional measures (e.g., vertical diameter, expanded horizontal diameter, heart and respiratory rate) were recorded in the fifth channel.

Testing was initiated after $60 \mathrm{sec}$ light adaptation. $\mathrm{S}$ was instructed to estimate a $30-\mathrm{sec}$ interval without counting. Twenty sec after S's indication, he was asked to estimate $30 \mathrm{sec}$ by silent counting.

For Task 2, $S$ remembered four numbers presented 1 per sec by $E$, repeating the sequence at E's request $10 \mathrm{sec}$ later (Kahneman \& Beatty, 1966). Next, a 7-digit sequence was presented. Some Ss were then given one or more additional 7-digit sequences; others, one or more 7-digit reversal sequences.

Task 3 was multiplication (Hess \& Polt, 1964). S was instructed to answer as soon as possible after $E$ presented a problem. The first two items were similar $(4 \times 19 ; 7 \times 16)$; Item 3 was more difficult ( $3 \times 8 \times 17)$.

In Task 4, $S$ was given $10 \mathrm{sec}$ to formulate a definition for a word from the WAIS vocabulary test. For most Ss, three words were presented.

For Task $5, \mathrm{~S}$ was instructed to think about a pleasant personal experience (Bernick \& Oberlander, 1968). After 30 to $60 \mathrm{sec}$, depending on pupillary response, $S$ was asked to concentrate specifically and intensely on the emotion associated with the experience. One min later, $S$ was instructed to stop thinking and to count silently to 30 . The same procedure was repeated for an unpleasant experience.

Finally, $\mathbf{S}$ was informed that $\mathrm{E}$ would ask some questions, answers withheld until E's request. $E$ then posed a question aimed to embarrass or provoke S (e.g., "How old is your wife?"; "What is your salary?"'). After 8 sec, E directed $S$ not to answer, announced that testing was completed, but asked $S$ to continue fixating while E varied illumination and checked pupillary adaptation.

Throughout testing $E$ waited until pupil size returned to normal before presenting each item. For Tasks 2, 3, and 4, E said, "Ready," 5 sec before presenting an item. Task order was varied for $10 \mathrm{Ss}$.

\section{Results and Discussion}

Because results were so consistent across Ss, records were analyzed quantitatively for only $16 \mathrm{Ss}$, tabulating pupil size directly from the record to the nearest $0.1 \mathrm{~mm}$. Each item was divided into a 10-sec baseline interval (B) preceding E's "Ready" or "Start"; a 5-sec "Ready" interval (R), where appropriate; and a performance interval $(P)$ which varied according to task. For $R$ and $P$ intervals the largest or smallest value (depending on overall trend) sustained for two or more seconds was tabulated.

Pupil diameter increased slightly ( $7 \%$ average) for most Ss during the initial time-estimate item, but not during time-estimation by counting. When time-estimation was not the initial task, there was no pupillary response, suggesting the $7 \%$ increase reflects "warm up" or novelty. Since counting elicited no pupil changes in initial Ss, silent counting was used subsequently to "occupy S's thoughts" and return pupil size to baseline when a change persisted after completing an item.

With very few exceptions, pupils dilated slightly (4\% average) during interval $\mathrm{R}$, and markedly during $\mathbf{P}$ for number memory, multiplication, and word definition, supporting Kahneman \& Beatty (1966) and Hess \& Polt (1964). Dilation during $P$ occasionally ranged to more than $100 \%$ of baseline, but mean increase was $25 \%$ to $30 \%$. Item difficulty, adaptation, and novelty influenced magnitude of change. For example, 4-digit memory elicited a mean increase of $15 \%$; 7-digits elicited a $29 \%$ mean increase; additional 7-digit sequences elicited smaller mean increases. Subsequently, the more difficult 7 -digit reversal resulted in a $27 \%$ increase, but an additional 7 -digit reversal elicited a smaller, $24 \%$ mean increase.

Influence of task difficulty and novelty is illustrated in Table 1. During the first multiplication problem average dilation was $30 \%$; the second problem elicited a smaller, $22 \%$ increase; the more difficult third problem elicited a $31 \%$ mean increase. Consistency of responses is also apparent in Table 1: Dilation occurred in all but three cases.

Table 1

Pupil Diameters ( $\mathrm{mm}$ ) during Multiplication.

S, Subjects; B and P, Baseline and Performance intervals, respectively; $\% \Delta=\mathbf{P}-\mathbf{B} / \mathbf{B} \times 100 ;$ - Pupil too variable to measure.

\begin{tabular}{|c|c|c|c|c|c|c|c|c|c|}
\hline \multirow[b]{2}{*}{$\mathbf{S}$} & \multicolumn{3}{|c|}{ Item 1} & \multicolumn{3}{|c|}{ Item 2} & \multicolumn{3}{|c|}{ Item 3} \\
\hline & B & $\mathbf{P}$ & $\% \Delta$ & B & $\mathbf{P}$ & $\% \Delta$ & B & $\mathbf{P}$ & $\% \Delta$ \\
\hline 1 & 4.2 & 6.0 & 43 & 5.5 & 5.5 & 0 & 5.0 & 5.5 & 10 \\
\hline 2 & 5.3 & 6.5 & 22 & 6.0 & 6.4 & 7 & 5.5 & 6.2 & 12 \\
\hline 3 & 6.1 & 6.7 & 10 & 6.0 & 7.2 & 20 & \multicolumn{3}{|c|}{ No Third Item } \\
\hline 4 & 3.5 & 6.0 & 72 & 6.8 & 6.5 & -4 & 5.0 & 6.8 & 36 \\
\hline 5 & 5.2 & 7.0 & 35 & 5.3 & 7.2 & 36 & 5.6 & 7.2 & 30 \\
\hline 6 & 5.0 & 6.2 & 24 & 4.0 & 5.8 & 45 & 4.5 & 5.8 & 29 \\
\hline 7 & 5.0 & 7.0 & 40 & 5.5 & 7.0 & 27 & 3.5 & 7.8 & 123 \\
\hline 8 & 4.5 & 5.0 & 11 & 5.0 & 5.0 & 0 & 5.5 & 6.0 & 9 \\
\hline 9 & 6.0 & 7.4 & 23 & 4.8 & 7.2 & 50 & \multicolumn{3}{|c|}{ No Third Item } \\
\hline 10 & 3.0 & 5.8 & 93 & 3.5 & 5.5 & 57 & 3.5 & 6.0 & 72 \\
\hline 11 & 6.0 & 7.2 & 20 & 6.2 & 7.0 & 13 & 6.0 & 6.8 & 13 \\
\hline 12 & 6.0 & 7.0 & 17 & $*$ & 7.0 & - & 6.0 & 7.0 & 17 \\
\hline 13 & 4.6 & 5.5 & 20 & 4.8 & 5.2 & 8 & 4.6 & 5.2 & 13 \\
\hline 14 & 4.2 & 7.1 & 69 & 4.5 & 5.5 & 6 & 4.5 & 5.6 & 25 \\
\hline 15 & 4.0 & 5.0 & 25 & 2.8 & 4.5 & 61 & 3.0 & 4.8 & 60 \\
\hline 16 & 6.5 & 7.0 & 8 & 5.0 & 6.5 & 30 & 4.0 & 6.0 & 50 \\
\hline$\overline{\mathbf{X}}$ & 4.9 & 6.4 & 31 & 5.1 & 6.2 & 22 & 4.7 & 6.2 & 32 \\
\hline
\end{tabular}


A close relationship (Hess \& Polt, 1964) between mental processes and pupil size was apparent during number memory. Some Ss showed increasing dilation throughout E's presentation, but a return toward base level until renewed dilation at recall. Some of these Ss, when questioned, revealed they had somehow "fixed" the memory (e.g., by grouping). Dilation was sustained if $S$ repeated the series until recall. Similarly, word definition sometimes elicited only a transient dilation and questioning revealed that $S$ had quickly found a good synonym or phrase; dilation was sustained if $S$ formulated his definition throughout the 10 -sec period. In the few instances of no dilation, Ss reported they had not attempted a definition.

Results were less clear during thoughts of pleasant or unpleasant experiences. Approximately one-third of the Ss dilated, one-third constricted, and one-third showed no change. There was no consistency within Ss or tasks: Some Ss showed change in one direction during pleasant thoughts, and no change, or opposite change during unpleasant thoughts; others showed similar changes on both tasks. Although some Ss stated they could not concentrate effectively, there was no apparent relationship between S's subjective feelings and his pupillary response. These results contradict Bernick \& Oberlander (1968), who reported dilation during both tasks in medical students. Our more heterogeneous Ss were not required to verbalize their thoughts, and the relationship between $S$ and $E$ was that of coworker, not professor and student, suggesting the importance of "set" or expectations in S's reactions (Schaefer \& Bernick, 1965).

Almost without exception, the loaded question elicited marked dilation, averaging $30 \%$. This may be evidence that pupillary response is related to emotional reactions, but a loaded question may also initiate thought processes evoking dilation as in problem solving.

The new electronic oculo-pupillometer has advantages over photographic devices. Continuous graphic display of pupil size and eye movements permitted $E$ to monitor S's responses on-line and, accordingly, present stimuli or questions about thought processes. The graphic record facilitated rapid, economical analysis of data. REFERENCES

BERNICK, N., \& OBERLANDER, M. Effect of verbalization and two different modes of experiencing on pupil size. Percept. \& Psychophys., 1968,3 , in press.

HESS, E. H., \& POLT, J. M. Pupil size in relation to mental activity during problem solving. Science, 1964, 143, 1190-1192.

KAHNEMAN, D., \& BEATTY, J. Pupil diameter and load on memory. Science, 1966, 154, 1583-1585.

SCHAEFER, T., \& BERNICK, N. Sensory deprivation and its effect on perception. In P. Hoch \& J. Zubin (Eds.), Psychopathology of perception. New York: Grune \& Stratton, 1965. Pp. 203-221. 